\title{
A CRISE ATUAL DO CAPITAL NA CONFORMAÇÃO DO ESTADO CONTEMPORÂNEO E GESTÃO DA EDUCAÇÃO
}

\author{
Terezinha Fátima Andrade Monteiro dos Santos \\ Universidade Federal do Pará (UFPA)
}

\begin{abstract}
A CRISE ATUAL DO CAPITAL NA CONFORMAÇÃO DO ESTADO CONTEMPORÂNEO E GESTÃO DA EDUCAÇÃO
Resumo: O trabalho resulta de estudos, cujo objetivo foi analisar o Estado contemporâneo em sua conformação diante da crise atual do capital, na perspectiva da gestão da educação.Considera que dentro da nova institucionalidade configurada pelo capital, já está incorporada uma lógica mercantil perversa, induzida por diversos meios e formas, seja pelos mass media, seja por meio de programas de financiamento, que condicionam as instituições públicas a assumirem a gestão gerencial, o planejamento estratégico, a cultura da avaliação (benchmarking), o incentivo ao individualismo, por meio do empreendedorismo, demonstrando que os desafios estão aí para quem quiser e puder se adequar. Além de ressaltar o papel significativo da educação nesse contexto, conclui que nas instituições de educação superior essa lógica já é mais visível, enquanto na escola básica está sendo incorporada paulatinamente.
\end{abstract}

Palavras-chave: Estado, crise do capital, gestão da educação.

\section{CURRENT CRISIS OF CAPITAL IN FORMING OF CONTEMPORARY STATE AND MANAGEMENT EDUCATION}

Abstract: Resulting clipping of studies, aimed to examine the contemporary state in its conformation before the current crisis of capital, in the perspective of management education. Within the new institutional set by capital, we have incorporated commercial perverse logic induced by various means and ways, either by the media, whether through funding programs that influence public institutions to assume managerial organization, strategic planning, the culture of evaluation (benchmarking), encouraging individualism, through entrepreneurship, demonstrating that the challenges are there for those who want and can fit. Education in every way plays a significant role in this context. In institutions of higher education is more visible now, but in elementary school is being built such logic gradually.

Keywords: State, crisis of capital, management education 


\section{INTRODUÇÃO}

Este trabalho é um recorte, oriundo de estudos por nós realizados, cujo objetivo foi analisar o Estado contemporâneo diante da crise do capital, na perspectiva da administração do processo e, especialmente, da educação. Privilegiou técnicas qualitativas de análise, o que nos permitiu alcançar as múltiplas dimensões da administração do Estado e da crise do capital, com foco na gestão da educação, por meio de documentos e uma extensa literatura sobre a temática proposta, com destaque para autores do liberalismo clássico como John Locke e de Karl Marx e marxistas como Eric Hobsbawm, Istvan Mészaros e educadores brasileiros, como Vitor Paro, Luiz Antonio Cunha, Silva Jr, Gaudêncio Frigotto, dentre outros.

Para analisarmos a conformação do Estado, faremos breve contextualização do novo momento vivido pelo capital, para mostrar que as configurações assumidas pelo Estado são dinâmicas e estão em sintonia com as mudanças socioeconômicas que representam os interesses de determinados setores que detêm o poder político e desenham o tipo de Estado, pois, como nos revela Marx (1978) o Estado moderno, como instituição política do capitalismo, é a síntese dos antagonismos de classes. Perguntamos, então: que novos tempos são estes?

\section{MEANDROS DA CRISE}

Num esforço de desvelar os meandros da crise do capítal, torna-se imprescindível buscarmos compreender o político-econômico na totalidade das relações capitalistas de produção. Em tal perspectiva, Marx (1982, p. 36) pode nos ajudar na análise, quando afirma que:

\begin{abstract}
A estrutura social e o Estado nascem constantemente do processo de vida de indivíduos determinados, mas destes indivíduos não como podem aparecer na imaginação própria ou alheia, mas tal e como realmente são, isto é, tal como atuam e produzem materialmente e, portanto, tal como desenvolvem suas atividades sob determinados limites, pressupostos e condições materiais, independentes de sua vontade.
\end{abstract}

As nossas práticas e o que pensamos estão articulados com nossa atividade material - o trabalho, da forma como o realizamos, pois o ser dos homens é o seu processo de vida real. Ora, como na sociedade capitalista tal produção se efetiva numa relação antagônica de apropriação e de expropriação, de desigualdades e de dominação, as relações sociais derivadas deste processo são relações de força e de poder e isto funciona dentro dos países e, destes para fora, no intercâmbio material dos homens.
[...] Mas os homens, ao desenvolverem sua produção material e seu intercâmbio material, transformam também, com esta sua realidade, seu pensar e os produtos de seu pensar (MARX, 1982, p. 37).

Como sabemos, a globalização ou mundialização não é algo novo. Na compreensão dos fundamentos dessa constatação, a análise de Marx e Engels (2008, p. 14) é bastante esclarecedora:

A necessidade de mercados sempre crescentes para seus produtos impele a burguesia a conquistar todo o globo terrestre. Ela precisa stabelecer-se, explorar e criar vínculos em todos os lugares.

Mas, na contemporaneidade, a globalização ou mundialização tem nuances e conformações diferentes. $\mathrm{O}$ desenvolvimento científicotecnológico avança numa progressão até antes, talvez, inimaginável, Hoje, por exemplo, no campo eletro-eletrônico, quando determinados produtos chegam ao mercado já se encontram obsoletos ${ }^{1}$. Também temos um sistema de comunicações fantástico, muita informação instantânea, maior velocidade na distribuição e circulação de produtos e serviços. Consoante à dinâmica societal, relações hegemônicas de poder incidem sobre tal desenvolvimento. Nesse prisma, registra-se a configuração de uma rede mundial de computadores sob o comando dos Estados Unidos, mediante a existência do software denominado "xkeyscore", capaz de controle total sobre a Internet. Tratate, portanto, de um sistema de dominação e controle cada vez maior, ainda que envolto numa crise estrutural do capital, que se arrasta desde o ínicio dos anos oitenta, sofrendo mudanças, que culimaram com a dos anos 2008.

Em função da crise estrutural do capital tem-se a reestruturação produtiva, as reformas do Estado e a crescente globalização. No intuito de conter a queda nas taxas de lucro das empresas e o endividamento crescente dos Estados nacionais, o toyotismo e o neoliberalismo buscaram superar o fordismo/keynesianismo como paradigma produtivo dominante e o Estado de Bem-Estar como modelo de gestão estatal e regulação social.

A palavra de ordem passou a ser flexibilidade: a produção precisa ajustar-se a demandas e mercados de trabalho flexíveis, destacandose as relações com o trabalhador, que precisa ser multifuncional, diferente, por conseguinte, do trabalhador especializado taylorista-fordista. Também, nesse contexto, o Estado deve investir menos nas áreas sociais e privilegiar estratégias de financiamento da acumulação privada por meio do fundo público. A tais diretrizes amplas e gerais, cada país, em particular, procurou se ajustar. 


\section{ESTADO BRASILEIRO, CIDADANIA E GESTÃO DA EDUCAÇÃO}

No Brasil (2013), ainda vivemos o desafio de construir uma sociedade democrática, desde 05 de outubro de 1988, quando promulgamos uma Constituição Federal, por meio de um projeto de democracia social para construção de uma nova institucionalidade, sob o imperativo da justiça social, na perspectiva de um novo marco regulatório de políticas públicas sociais, embora não tenhamos constituido um Estado do Bem-Estar Social, mas um Estado desenvolvimentista, que também teve o planejamento central, com políticas de intervenção, que beneficou o capital e a reprodução da força de trabalho. Continuamos lutando para o alargamento de nossos direitos, como parte intrínseca da essência da democracia, sem os quais esta dificilmente se concretizaria, ainda que na perspectiva liberal. Expressam-se como direitos sociais que não se resumem a tais garantias prescritas em leis, normas ou instituições. Extrapolam a isto na perspecttiva de construção de uma nova sociabilidade, segundo (DAHL, 2001).

Neste sentido, alguns direitos foram conquistados sem estarem, entretanto, subsumidos exclusivamente à ordem econômica, mas como direitos de cidadania (para todos, em tese), como qualidade política identificatória e a educação se insere neste contexto, como parte de responsabilidade do Estado capitalista, assegurados na lei (Constituição Federal de 1988 que é liberal), que nos faz remeter a John Locke (2009) quando diz que o Estado é a estrutura máxima do poder político, após o pacto que os homens fizeram para viver em sociedade política, para salvaguardar sua propriedade, visando o bem público:

A essência da liberdade política na verdade, é que o homem não deverá estar sujeito à vontade inconstante, incerta, desconhecida e arbitrária de outro homem. A lei não é incompatível com a liberdade, ao contrário, é indispensável a ela, pois o "objetivo de uma lei não é abolir ou restringir, mas preservar e ampliar a liberdade [...] Pois a liberdade deve ser livre de restrição e violência por parte dos outros, o que não pode existir onde não há lei. (LOCKE, 2009, p. 7).

Observe-se que a garantia constitucional desses direitos de cidadania, no Brasil, deu-se num momento em que o mundo já vivia uma situação de crise não favorável à igualdade, daí não termos, em grande medida, conseguido fazer com que os direitos sociais fossem efetivamente exercitados na concretude de nossa vida material, mesmo nos limites do capital. As lutas são contínuas, com foco no seu alargamento constante. A crise estrutural do sócio-metabolismo do capital iniciada nos início dos anos oitenta, como nos diz Mészàros (2009), rebate fortemente neste contexto brasileiro subvertendo as condições necessárias para que o projeto social se efetivasse.

Os organismos internacionais do capital, como o Fundo Monetário Internacional, o Banco Mundial e outros exigem dos países sob seu domínio, especialmente os considerados em desenvolvimento, um novo marco regulatório e se não o fazem diretamente, recomendam por intermédio de diferentes estratégias. Para delimitarmos tal contexto, primeiro conformaremos tal regulação, a partir de alguns pressupostos, pois envolve um conjunto significativo de configurações, além de diferentes dimensões, quer seja no campo de intervenção do Estado, quer seja no seu oposto de libertação da sociedade dos domínios do Estado.

Portanto, a regulação social no Brasil vem se conformando por meio de medidas políticas e administrativas, de caráter técnico, políticoideológico, filosófico-cultural, dentre outros, que se concretizam a partir de justificativas advindas da necessidade de modernizar o aparelho estatal, desburocratizando-o, para que se torne mais eficiente e ágil e mais próximo da sociedade - nova forma de gestão do público, "gestão gerencial"; a perspectiva de um novo projeto de sociedade decorrente do desenvolvimento da ciência e da tecnologia, pela necessidade de inserção no mercado global altamente competittivo. A justificativa da necessidade ética de participação da sociedade se responsabilizando conjuntamente com o Estado, pelas políticas sociais, é uma teia estruturada para demarcar um novo momento.

É uma nova materialidade que é produzida para formar o "[...] pensamento único e solução para a crise estrutural do Sistema Capital." (FRIGOTTO apud GURGEL, 2003, Prefácio) que se efetiva por meio de diferentes mecanismos, estratégias e espaços, configurando uma nova Gramática histórico-geográfica para cumprir sua função ideológica e formar uma consciência social - forjando visões de mundo e compactando intervenções na sociedade, ideologicamente divulgada nos diferentes espaços sociais, por meio de conceitos e expressões que passam a ser usados em diferentes contextos, como: Estado mínimo, globalização, inovação, multifuncionalidade, terceirização, reengenharia, reestruturação produtiva, sociedade do conhecimento, flexibilidade, qualidade total, competências, empregabilidade, empreendedorismo, parcerias público-privadas, responsabilidade social, terceira via, accountibility, governação, sustentabilidade, o público não-estatal, benchmarking, dentre outros (SANTOS, 2012). Ressalte-se a grande falácia disseminada para a população de que a educação é fator por excelência da empregabilidade (empregar-se e se manter no emprego) (FRIGOTTO, 2003). 
Silva Jr (2002, p. 30) nos alerta sobre tal momento do capital, com a construção de um novo "pacto social" em que se observa a mercantilização da esfera pública:

Como na conjuntura atual, quando de fato a racionalidade educacional alinha-se à racionalidade das grandes transformações em curso no capitalismo mundial: a mercantilização das eferas sociais e políticas, a consolidação da extended order de Hayek.

A extended order (ordem estendida do mercado) seria uma adaptação às atividades humanas realizada pelo mercado, o que foi concretizado pelo Estado, especialmente, nos países periféricos. Foram mudanças significativas no mercado de trabalho, legislação trabalhista e nos aparelhos estatais, dentre outras (SILVA JR, 2002).

Após abril de 2009, mais sistematicamente, pela divulgação feita na imprensa mundial e, em particular, brasileira, pensávamos ter sido superado o Consenso de Washington por um novo, o de Londres, firmado a partir de uma reunião do Grupo dos 20 - G20 (maiores potências do capitalismo mundial), sob a coordenação do $1^{\circ}$ Ministro inglês (2007-2011) Gordon Brown, mas o proposto não ocorreu, pois o que vimos, também disseminado pela imprensa, foi um novo jogo de marketing pirotécnico para fazer, o mundo em crise violenta, acreditar em novas saídas, consensuadas pelos homens de negócios, que se preocupam com os destinos das formações sociais que representam e, notadamente, de suas populações. Lá se definiram princípios e valores para regular o capital, baseados no tripé pessoa-planeta-lucro - sustentabilidade, sem definir ao certo que princípios e valores são estes e como farão a regulação, a partir de que estratégias e instrumentos de gestão e quem os definirão, como novas alternativas de crescimento econômico.

Para o historiador Eric Hobsbawm (1992, p. 270), o "[...] desenvolvimento sustentável não pode operar através do mercado, mas deve operar contra ele." Perguntaríamos: como exercitar a sustentabilidade em uma sociedade que se alimenta da abundância, do consumo crescente e exacerbado, cujos pilares se assentam na produção-consumomais produção-mais consumo? Como se falar em sustentabilidade num processo de insustentabilidade crescente? Sem quebrar esse ciclo tudo parece apenas fantasia e jogo de palavras.

Voltando ao problema da nova Gramática do capital, temos uma regulação expressa num conjunto de dispositivos, regras, normas, estratégias, instrumentos codificados sob diferentes formas, que envolvem desde a regulamentação o arcabouço jurídico, passando pelas culturas institucionais, a correlação de forças políticas e outros elementos.

Na verdade, não dá para falarmos em uma regulação social, mas, de regulações sociais, pois, como sabemos, as políticas públicas, especialmente de gestão, que analisamos em nossas pesquisas ou estudos se expressam em documentos formais, por meio de discursos que, de alguma forma, tornam-se hegemônicos, a partir de orientações internacionais, mas que só serão políticas públicas sociais ao materializarem-se em ações concretas nas práticas, nos espaços para os quais foram definidas.

Nesse momento, outros fatores importantes interferem significativamente, fatores esses decisivos, como as culturas institucionais, a correlação de forças políticas, o nível de organização da comunidade envolvida e outros elementos (as instituições são historicamente determinadas, com suas especificidades próprias, termos são marcados pelas condições concretas de sua consecução), havendo uma permeabilidade para feições e nuances nem sempre coincidentes com as propostas definidas. É como se recompusessem de alguma forma as regras do jogo, mas mantendo a sua essência, sob pena de inviabilizar sua consecução (SANTOS, 2012).

Alguns consideravam e tentavam passar para a sociedade brasileira que bastava a igualdade no plano jurídico e a liberdade econômica (o mercado livre) que os homens viveriam mais felizes. Ficou evidente, com o desenvolvimento do capitalismo, que isto era uma falácia, que, para Konder (1980, p. 12):

[...] era preciso criar condições práticas, materiais, concretas, para assegurar aos homens uma vida decente e a efetiva possibilidade deles serem livre. A grande questão então é como conciliar direitos de cidadania com a lógica e ferocidade do mercado?

Neste sentido, ressalte-se que grande parte dos políticos que construíram a nossa Constituição Federal cidadã foram os que mais tarde fizeram coro para dizer que o Estado não teria condições de assegurar todos os direitos lá garantidos, legalmente; e conforme já explicitamos, o mundo já vivia o esgotamento do ideário fordista-keynesiano que pregava o pleno emprego, produção, consumo de massa e generosidade protetora do Estado, por meio de intervenções, para reprodução do capital e da força de trabalho, patrocinando políticas sociais de educação, saúde, seguridade social, habitação, e outras, com o financiamento do fundo público, bem como controlava salários e direitos trabalhistas. $\mathrm{O}$ planejamento passou a ser sacralizado como fator de prosperidade capitalista.

$\mathrm{Na}$ época, da promulgação da $\mathrm{CF}$, a classe política precisava dar uma resposta à sociedade que estava enjaulada há mais de vinte anos, embora soubesse que grande parte do que foi preconizado ficaria apenas na letra morta da lei. É uma mistificação até mesmo ao afirmarem que o Estado 
brasileiro é laico e invocam uma crença monoteísta no preâmbulo da CF de 1988:

Nós representantes do povo brasileiro, reunidos em Assembleia Nacional Constituinte para instituir um Estado Democrático, destinado a assegurar o exercício dos direitos sociais e individuais, a liberdade, a segurança, o bem-estar, o desenvolvimento, a igualdade e a justiça como valores supremos de uma sociedade fraterna, pluralista e sem preconceitos [...] promulgamos, sob a proteção de Deus, a seguinte CONSTITUIÇÃO DA REPÚBLICA FEDERATIVA DO BRASIL (BRASIL, 1988, grifo nosso).

No caso da educação, foi a partir da democratização do Brasil que foram garantidas medidas de democratização da gestão das unidades escolares, como: eleições para o provimento do cargo de diretor, construção coletiva do projeto políticopedagógico, criação de órgãos colegiados escolares, autonomia para tomar decisões administrativas, financeiras e pedagógicas, considerando-se os interesses da comunidade escolar, em benefício da melhoria da qualidade do ensino. Não desconhecemos, entretanto, que mesmo antes, já havia experiências de democratização na gestão de unidades escolares.

Silva (1996), ao examinar a questão da autonomia da escola pública, destaca três pontos como fundamentais para que ela se concretize: a noção de liberdade que é sempre relativa (capacidade de escolha); ideia de poder (capacidade de influenciar coisas e pessoas) e a responsabilidade para exercer essa autonomia. Para ele, autonomia é produto de toda uma caminhada, onde é necessário a participação ativa do sujeito, daí não poder ser implantada, mas decorrente de uma construção e conquista coletiva.

O Estado brasileiro, ao longo dos anos noventa estebeleceu algumas políticas tendo em vista, fazer com que as unidades escolares incorporassem novas práticas, a partir de Programas e/ou Projetos como Programa Dinheiro Direto na Escola, em que as escolas recebem recursos financeiros como uma das medidas racionalizadoras, menos burocráticas, de modo que os recursos chegassem com mais agilidade e diretamente às escolas, conforme Resolução FNDE $\mathrm{n}^{\circ} 12$, de 10 de maio de 1995 (BRASIL, 1995).

O Programa tem como objetivo repassar, diretamente às escolas públicas do ensino fundamental e organizações não-governamentais sem fins lucrativos que atuem com educação especial, dinheiro para custeio e manutenção de suas atividades, com recursos oriundos do salárioeducação ${ }^{2}$, distribuídos pelo Fundo Nacional de Desenvolvimento da Educação (FNDE) segundo o número de alunos matriculados.
Para se candidatar a receber tais recursos, as unidades educativas precisavam criar órgãos colegiados, que podem ser Conselhos Escolares, Associação de Pais e Mestres, Caixa Escolar ou outra modalidade, de acordo com os interesses daquelas instituições. Nesse sentido, os órgãos do Sistema patrocinaram tal criação, bancando até a formalização jurídica de tais colegiados.

Tivemos também o Plano de Desenvolvimento da Escola PDE-Escola, considerando a necessidade de fortalecer a sua gestão, para a melhoria dos resultados, com o apoio técnico da Secretaria Municipal ou Estadual de Educação, "em regime de colaboração" com a União, objetivando a incorporação do planejamento estratégico nas escolas, na perspectiva gerencial, de criação de metas a cumprir, de geração de resultados quantitativos, introduzindo assim, uma nova lógica nas relações escolares. Uma outra política importante foi a das parcerias público-privadas, que deram abertura para entidades ditas sem fins lucrativos celebrarem contratos para apoiar a as ações escolares, como vem fazendo o Instituto Ayrton Senna, a Fundação vale, Itaú Social, dentre outros.

Entretanto, as pesquisas ${ }^{3}$ revelaram que, passados mais de vinte anos //ainda não conseguimos realizar, em práticas concretas, a maior parte das políticas, que se transformaram em meras formalidades estéreis, que servem para as unidades escolares serem aquinhoadas com recursos financeiros, com a inserção de novos projetos, dentre outros. Não democratizamos as relações, e já estamos incorporando uma nova lógica que vem embutida não só nos Programas dirigidos à melhoria da gestão, como a das parcerias públicoprivadas, outras políticas, como as de avaliação em larga escala, geradora de um processo de individualismo exacerbado, do conhecimento útil, da competitividade dentro das próprias escolas e na relação com as outras.

Desse modo, tivemos mudanças significativas na gestão das instituições públicas brasileiras, chegando à educação, numa nova concepção de administração centrada nos resultados que o Plano Diretor de Reforma do Aparelho Estatal do governo Fernando Henrique Cardoso (1995-2002) denomina de gerencial, nos moldes empresariais aproximados ao tipo toyotista, da qualidade total para satisfação dos clientes dos serviços prestados pelo Estado, em nome da necessidade de diminuição dos desperdícios, do melhor aproveitamento do tempo, do espaço, dos recursos materiais e humanos, da maior produtividade, na busca de excelência, com a redução dos gastos públicos - é uma nova racionalização (otimização dos recursos e maximização dos resultados).

Sem democratizarmos efetivamente as relações de poder em nossas escolas públicas, já estamos passando para outras formas de gestão, mais afinadas com a acumulação flexível. 
São novos conceitos, métodos e técnicas exigidas pelo novo momento do capital globalizado (neoliberalismo). Isso depende de um sistema de regras formais calculáveis para o controle do trabalho pela administração, que desloca seu foco do processo para o resultado. É um novo sistema de organização do trabalho, que se expressa em novas configurações e ampliação do público, que retoma ao liberalismo clássico de Locke, em que a esfera pública se amplia, com sua redefinição para sociedade civil que atua na perspectiva do bemcomum, criando a figura do público não estatal. Aliás, o campo da gestão empresarial é muito dinâmico e cada dia novos conceitos, técnicas, estratégias são criadas, para dar conta do mercado flexível, e os defensores da lógica do mercado nas relações entre Estado e sociedade tentam implementar, em nome da eficiência, eficácia e produtividade.

Apesar de as determinações do mundo do capital repercutirem noutros mundos como o da educação, por exemplo, não devemos considerar que há uma correia direta de transmissão entre a produção e as políticas educacionais que chegam à escola, mais especificamente, porque existem mediações importantes em tal relação

[...] que têm muitas vezes, sua própria lógica. Mais do que linhas de transmissão entre dois vetores de força, elas modificam as forças que recebem e acabam por exercer suas próprias forças,[...]" (CUNHA, 2002, p. 21).

A gestão escolar dominante ainda é a tradicional, centralizada na figura do diretor, o que não quer dizer que uma nova lógica não esteja sendo incorporada.

Ao lado dessas mudanças, das novas formas de sociabilidade, temos, talvez outras mais graves que, em tese, não estão sendo analisadas, nem valorizadas, que é a articulação perversa entre um moralismo religioso e a política, apesar dos avanços das garantias dos direitos das minorias. São pequenos avanços e, contraditoriamente, recuos quando se misturam religião com política, que podem nos levar a caminhos perigosos e tortuosos de lutas segregacionistas, apesar de o próprio governo brasileiro incentivar a tolerância, o respeito à diversidade, com a criação de políticas de atendimento a segmentos discriminados, ao longo de nossa história.

Tal retrocesso só faz aumentar o fosso da desigualdade entre as elites e classes populares, mesmo com o discurso da ascensão de uma nova classe média, como se esta pudesse ser definida pelo rendimento familiar, contraditoriamente ainda muito miserável, ainda que consideremos que houve alguma melhora para os mais miseráveis, em termos de inserção num mundo do consumo de alguns bens, até então inacessíveis, como telefone, televisão, geladeira e outros. Parte do fundo público serve para financiar parcialmente tais bens, que servem muito mais à acumulação de capital.

Além disso, a tal articulação religião-política é mais um entrave para o efetivo desenvolvimento social, mesmo nos moldes do capital.

\section{CONCLUSÃO}

Dentro da nova institucionalidade configurada pelo capital, temos já incorporada uma lógica mercantil perversa, induzida por diversos meios e formas, seja pelos mass media, seja por meio de programas de financiamento, que condicionam as instituições públicas a assumirem a gestão gerencial, o planejamento estratégico, a cultura da avaliação (benchmarking), o incentivo ao individualismo, por meio do empreendedorismo, demonstrando que os desafios estão aí para quem quiser e puder se adequar. A educação em todos os sentidos tem papel significativo neste contexto. Nas instituições de educação superior já é mais visível tal perspectiva, mas na escola básica está sendo incorporada tal lógica, paulatinamente, embora ainda tenhamos o modelo tradicional de gestão escolar dominante, no qual o diretor ou gestor escolar é a figura central da unidade escolar.

As novas formas de organização do trabalho e da vida em seu sentido amplo vêm sendo incutidas em todos, mesmo naqueles mais críticos, sem que muitas vezes se apercebam - o poder da ideologia é forte. Nesse sentido, temos reality shows, como o Big Brother Brasil da Rede Globo de Televisão (em 2012, crazy - louco), como dimensão perversa da precariedade da força de trabalho, ao mostrar lição de fácil aprendizagem, que só aqueles que possuem determinados predicados, habilidades e outras qualidades excepcionais poderão ser premiados, e os outros serão aqueles descartáveis pelos paredões (empregabilidade - condições de ingressar no mercado e nele se manter), é uma imagem forte, que pode produzir graves resultados nem um pouco afinados com os ideais de solidariedade, de igualdade, da ética com estética (dimensão humana espiritual) e que atingem o subjetivo das pessoas. O trabalho, neste novo momento do capital, perde sua mediação pública, mas não seu papel para criar valor.

É trabalho temporário, contratos de gestão, terceirização já em nova modalidade, em que os trabalhadores altamente qualificados não têm mais contrato de trabalho, mas constituem empresas que prestam um serviço (os antigos colaboradores agora são associados).Não se tem mais um exército de reserva, mas um exército de excluídos, que não mais terão espaço no mercado de trabalho, que ficarão vivendo à beira do capital, em geral na dita informalidade, nas suas estratégias de sobrevivência. Portanto, a palavra de ordem é se qualificar infinitamente, para demonstrar diferencial, mesmo sem ter postos de trabalho para todos. 
O paredão está aí, intimidando e assombrando. Este é o novo tempo do capital, é a sustentabilidade. Só falta dizer: de quem ou do quê? Os princípios e valores estão aí: o consumismo exacerbado, depois vêm os seus antídotos criados pelos mesmos senhores (os países hegemônicos), o empreendedorismo, as parcerias público-privadas, o sucesso como prêmio ao seu esforço, dedicação, equilíbrio emocional, espírito inovador e criativo, enfim, possuidor de uma performance que serve à sociedade da imagem ideológica.

Isso tudo precisa ser administrado, todos precisam gerir suas vidas. Gestão é palavra de ordem, mas não qualquer tipo de gestão, benchmarking (técnica de gestão estratégica), do negócio social (resultado e impacto hojenaperspectivadasocial positivo). Necessitase disso para a concretização dos requerimentos de nova sociabilidade do capital. As instituições públicas precisam ser competentes, eficientes e produzir resultados como qualquer organização mercadológica, absorvendo e disseminando um produtivismo crescente. Temos de ser o melhor do melhor.

\section{REFERÊNCIAS}

BRASIL, Presidência da República. Constituição Federal do Brasil, 1988, Brasília, DF: Imprensa Oficial.

Ministério da Administração e Reforma do Estado. Plano Diretor da Reforma do Aparelho do Estado. Brasília, DF: MARE, 1995.

Medida Provisória $n^{\circ} 1.784$, de 14 de dezembro de 1998. Dispõe sobre o repasse de recursos financeiros do Programa Nacional de Alimentação Escolar, institui o Programa Dinheiro Direto na Escola e dá outras providências. Publicada no D.O.U de 15/12/98.

MEC-FNDE. Resolução FNDE $\mathbf{n}^{\circ} \mathbf{1 2}$, de 10 de maio de 1995, Brasília, DF, 1995.

CUNHA, Luiz Antonio. Mediações na articulação trabalho-educação. Trabalho e Educação, Belo Horizonte, n. 10, jan.-jun - 2002.

DAHL, R. A. Sobre a democracia. Tradução de Beatriz Sidou. Brasília: Editora Universidade de Brasília, 2001.

GURGEL, Cláudio. A gerência do pensamento: gestão contemporânea e consciência neoliberal. São Paulo: Cortez editora, 2003.

FRIGOTTO, Gaudêncio. Prefácio, in: GURGEL, Cláudio. A Gerência do Pensamento: gestão contemporânea e consciência neoliberal. São Paulo: Cortez, 2003, p. 11-19.
HOBSBAWM, Eric. Renascer das cinzas. In: BLACKBURN, Robin. Depois da queda: o fracasso do comunismo e o futuro do socialismo. Rio de Janeiro: Paz e Terra, 1992.

KONDER, Leandro. A democracia e os comunistas no Brasil. Rio de Janeiro: Edições Graal, 1980.

LOCKE, John. Segundo Tratado sobre o Governo Civil. Tradução: Magda Lopes e Marisa Lobo da Costa. Rio de Janeiro: Editora Vozes, vol. 8 n. 1, 2009.

MARX, Karl; ENGELS, Friederich. A Ideologia Alemã. Tradução de José Carlos Bruni e Marco Aurélio Nogueira. $3^{a}$ edição. São Paulo: Livraria Editora Ciências Humanas, 1982.

\section{O Manifesto do Partido}

Comunista. São Paulo: Editora Expressão Popular, 2008.

MÉSZÁROS, István A crise estrutural do capital. Tradução de Francisco Raul Cornejo. São Paulo: Boitempo, 2009.

SANTOS, Terezinha F. A. Monteiro dos. A construção da gestão democrática em unidades escolares e o novo tempo para o capital. Revista Educação e Políticas em Debate - Minas Gerais, v. 1, n. 1, p.187-203, jan./jul. 2012.

SILVA JÚNIOR, João dos Reis. Reforma do Estado e da Educação no Brasil de FHC. São Paulo: Xamã, 2002.

\section{NOTAS}

1 Há obsolescência programada, a percebida e a divulgada, que a nosso ver, formam uma unidade

2 O salário-educação foi instituído pela Lei no 4440 , de 27 de outubro de 1964, sendo uma contribuição social correspondente a $2,5 \%$ da folha de pagamento das empresas vinculadas à Previdência Social.

3 SANTOS, T. Pesquisas realizadas pelo Observatório de Gestão democrática da UFPA, divulgadas em Conversas impetnintentes sobre a gestão na educação. EDUFPA: Belém, 2008 e SANTOS \& LIMA. Versus e Reversus da gestão das políticas educacionais.Ponto Press Ltda: Belém, 2012, p.11-30

Terezinha Fátima Andrade Monteiro dos Santos Bacharel em Letras

Doutora em Educação pela Universidade Metodista de Piracicaba

Professora da Universidade Federal do Pará

E-mail:tefam@ufpa.br

Universidade Federal do Pará - UFPA

Av. Almirante Barroso, 1155 - Marco

CEP: 66093-020-Belém-PA 